\title{
In silico Characterization, Homology Modeling and Virtual Screening of Selected Natural Compounds as Modulators of Salmo salar and Teratodon nigrovirdis Tyrosinase Protein
}

\author{
Riya Kumari $^{1 *}$ and Sujit Kumar ${ }^{2}$ \\ ${ }^{1}$ Department of Fish Genetics and Biotechnology, ICAR-Central Institute of Fisheries \\ Education, Versova, Mumbai, India-400061 \\ ${ }^{2}$ Department of Fish Biotechnology, PGIFER, Kamdhenu University, \\ Gandhinagar, Gujarat, India \\ *Corresponding author
}

\section{A B S T R A C T}

\section{Keywords}

Teratodon nigrovirdis, Salmo salar, Tyrosinase, Chromatophores Bioinformatics, Homology modeling, Virtual screening

\section{Article Info}

Accepted: 05 February 2020 Available Online: 10 March 2020
Colour patterns are the most distinct phenotypic traits in the majority of the living organism including fishes and considered as one of the main influencing factors in consumers' buying decisions. Color traits are regulated by mainly four types of pigments stored in chromatophores. Melanin, is one of the most important pigment of cells, responsible for the coloration. Tyrosinase is a characteristics enzyme in melanin biosynthesis. Modulation of tyrosinase is of significance in the ornamental fish industry, food fishes as well as in humans. By modulating the tyrosinase activity, it is possible to alter the body pigmentation and will help to develop different colour varities of fish and also treatment of hyper pigmentation disorder. The green spotted puffer fish (Teratodon nigrovirdis), an ornamental fish and Atlantic salmon (Salmo salar), an important aquaculture species were selected because of their commercial importance. The present study was aimed to characterize the tyrosinase enzyme of green spotted puffer fish (Teratodon nigrovirdis) and Atlantic salmon (Salmo salar) and to identify the natural compounds as putative modulators of tyrosinase. 3D models of tyrosinase protein were predicted by performing a comparative homology modeling program with the help of Chimera 1.1.3, Modeller and Swiss-model, and predicted structure was validated by the energy minimization method using SAVES Server including Procheck, Verify 3D and Errat tools. The physicochemical properties revealed that the fish tyrosinase protein is hydrophobic in nature, acidic, having a high extinction coefficient, unstable, thermolabile for a range of temperatures. The functional properties identified that T.nigrovirdis and $S$. salar tyrosinase protein sequence had transmembrane-segment and random coils dominated the secondary structure followed by an alpha helix, extended strands and beta turns. The results obtained from the Saves server showed that the models predicted by Swiss-model were more reliable compared to models developed by other tools. A structure-based virtual screening method helped to identify tyrosinase modulators. Three compounds out of 13000 from the ZINC database were identified as putative modulators of fish tyrosinase having binding energy $-8.7 \mathrm{Kcal} / \mathrm{mol}$ to $-8.2 \mathrm{Kcal} / \mathrm{mol}$. Among which, 3-Methyl-2phenylquinoline-4-carboxylic acid, 2-(4-chlorobenzyl)-5-(3-nitrophenyl)-2H-1,2,3,4-tetraazole and Kaempferol were considered as potential putative modulators as they had low binding energy and had acceptable properties for standardized drugs. Further, these compounds can be tested in-vivo for their efficacy and usefulness in altering the color pattern of the fishes. 


\section{Introduction}

Colour and its patterns are the most distinct phenotypic traits in the majority of the living organism including fishes and are the result of diverse pigments synthesized by chromatophores. Melanins are unique pigmented biopolymers synthesized by melanocytes and deposited within melanosomes. The chemical nature of melanin along with its size, number, shape and distribution governs skin pigmentation. Tyrosinase is one of the key enzyme of melanogenesis pathway where it oxidizes Ltyrosine to melanin. In melanogenesis, tyrosinase oxidizes tyrosine to dopaquinone; a reaction which is the rate-determining step in the synthesis of melanin since the remainder of the reaction sequence can spontaneously proceed at the physiological $\mathrm{pH}$ values (Halaban et al., 2002). Tyrosinase gene family is categorized into three groups viz., tyrosinase (Tyr, TYR), tyrosinase related protein-1(Tyrp-1, TYRP-1) and tyrosinase related protein-2 (trp-2, TRP-2) and widely available in plants, animals, microorganism, etc. ((Wang et al., 2007; Bagherzadeh et al., 2015). Tyrosinase plays a major role in photoprotection, and thermoregulation, however, the accumulation of the abnormal amounts of melanin in different parts of the skin results in various kinds of physiological conditions (Hasegawa, 2010; Rao et al., 2013). Alteration in melanin pigment synthesis also affects the appearance, taste, nutrition values of agricultural and horticultural goods and leads to economic loss (Artés et al., 1998). Color and its patterns are also the main influencing factors in consumers' buying decisions for food fishes as well as ornamental fishes. Therefore, introducing more efficient modulators is of great importance in medical products and industry including agricultural, aquaculture and cosmetics. Salmonids fish of the genera Salmo attract the attention of both researchers and the general public, on account of their biological characteristics and wide use in aquaculture, sport and recreational fishing, and research (Garcia de Leaniz et al., 2007). It has been widely reported that the melaninbased coloration in Salmo salar reduces their acceptability in the commercial market and it is of importance to understand the tyrosinase structure and functions along with its putative modulators which will help the salmon industry. The green spotted Teratodon nigrovirdis, an ornamental fish is a vertebrate model organism and the knowledge of tyrosinase of this species will help to extend it to other species also. Homology modeling and molecular docking have recently developed as a powerful method complementing traditional high through put screenings. Computational chemistry and chemo informatics play an important role in preliminary drug research. Keeping these points in mind the present study was taken up with objectives of In silico characterization, Homology modeling and virtual screening of selected natural compounds as modulators of Salmo salar and Teratodon nigrovirdis tyrosinase protein.

\section{Materials and Methods}

\section{Sequence retrieval}

The tyrosinase family like tyrosinase (tyr), tyrosinase related protein-1a (tyrp-1a, tyrp-1) tyrosinase related protein-1b (tyrp-1b) and Dct protein sequences of Teratodon nigrovirdis and Salmo salar retrieved in FASTA format from UniprotKB, a public domain protein database. Six unique proteins were selected and considered for this study (Table 1).

\section{Primary structure analysis}

The physicochemical parameters were computed using the Expasy's ProtParam tool (http://web.expasy.org/protparam/). 


\section{Transmembrane region analysis}

The identification of transmembrane regions of a protein was determined by the SOSUI server (harrier.nagahama-i-bio.ac.jp/sosui/). Hydrophobicity score and plot were obtained using the Kyte and Doolittle method by keeping a window size of 7 (Figure 1).

\section{Secondary structure analysis}

SOPMA server (https://npsa prabi.ibcp.fr/NPSA/npsa_sopma.html) was used to predict the secondary structure of the protein in the form of $\alpha$-helical, $\beta$-strand and coiled regions in percentages.

\section{Tertiary structure prediction}

The modeling of the 3D structure of the tyrosinase amino acid sequence of Teratodon nigrovirdis (H3CX59) and Salmo salar (Q19VI0) was predicted by SWISS-MODEL, and Chimera 1.1.2. The predicted model was validated by SAVES including PROCHECK, verify 3D, and ERRAT server. Python molecular viewer (PyMol) was used to visualize the tertiary structure of the protein (Sanner, 1999).

\section{Naturals compounds library preparation}

A total of 13000 natural compounds were downloaded from ZINC12 Database (www.zinc.org) in SDF format. The compounds were prepared for docking study into PDB format followed by PDBQT with the help of Openbabel software.

\section{Virtual screening and molecular docking}

Grid box, for docking, was made with the help of autodock tool 4.2. The docking was based on complete structure docking and at different active sites positions.

\section{Ligand prediction}

The criterion for selecting the ligands was based on their lowest binding efficiency, threshold value being $-7 \mathrm{kcal} / \mathrm{mol}$.

\section{Toxicity analysis}

Absorption, distribution, metabolism, excretion, and toxicity (ADMET) properties was tested by ADMETsar server and lipinski rule of five (www.scfbioiitd.res.in/software/drugdesign/li pinski.jsp).

\section{Results and Discussion}

\section{Primary structure analysis}

The primary structure analysis was done and different parameters computed using the Protparam tool were tabulated in table 2 . The analyses of the amino acid sequences revealed that the primary structure of the majority of the fish tyrosinase sequence is hydrophobic in nature due to the presence of high non-polar residue. Moreover, the primary structure analysis revealed that the Teratodon nigrovirdis and Salmo salar fish tyrosinase have high residues of acidic and basic amino acid, this might be involved in salt bridge formation.

\section{Physicochemical characteristics}

The Molecular weight of the protein was calculated by adding the average isotopic masses of amino acids in the target protein and the average isotopic mass of one water molecule. The value of molecular weight ranged from 47576 to 60985.88 Dalton (Table 2). Isoelectric point (pI) is the value at which the surface of the protein is covered with the charge but the negative and positive charges are equal hence, the net charge of the protein is zero. In the present study, the value of the 
Isoelectric point ranged from 5.44 to 6.15 (< 7) reveals that all of them are acidic in nature except Q19VI1 (Table 2). The calculated isoelectric point (pI) will be useful because at pI, solubility is least and mobility in an electro focusing system is zero (Arora et al., 2009). The extinction coefficient of tyrosinase at $280 \mathrm{~nm}$ is ranging from 75205 to 117185 $\mathrm{M}^{-1} \mathrm{~cm}^{-1}$ with respect to the concentration of Cys, Trp, and Tyr. The high extinction coefficient indicates the presence of a high concentration of Cys, Trp and Tyr. The Instability Indices (II) for the proteins was above 40 with the value ranging from 38.81 to 54.98 (Table 2), which indicated that they are less stable within a solution except for Q19VI1. All the proteins had negative Grand Average Hydropathy (GRAVY) scores with the value ranging from -0.230 to -0.413 , which meant that they are hydrophilic in nature and have better interaction with water. The Aliphatic Index (Ai) evaluates the relative volume of the protein occupied by the aliphatic side chains. Based on the results attained, it indicated that AI values were average with the value ranging from 68.75 to 78.88 , which indicated that the proteins would vary over an array of temperatures.

\section{Transmembrane analysis}

The SOSUI server performs the identification of transmembrane helices with their corresponding length and differentiates membrane proteins from soluble proteins (Hirokawa et al., 1998). The present study revealed that all selected proteins were membrane proteins having one transmembrane helix except Q19VI0 (Table $3)$. The transmembrane region predicted was found to be rich in hydrophobic amino acids and it is also validated by Kyte and Doolittle mean hydrophobicity plot (Figure 1) in which many points lie above the 0.0 line and a clear peak was observed in a plot that indicates about transmembrane helix.

\section{Secondary structure analysis}

SOPMA server was used to derive quantitative values for the number of alphahelices, beta sheets and coils present within the amino acid stretch of the protein. The predicted secondary structure of tyrosinase in the present study revealed that random coils dominated the secondary structure followed by the alpha helix, extended strands and beta turns for all sequences. While other features of secondary structure such as 310 helix, Pi helix, Ambiguous states, Bend region, and Beta Bridge were not found (Table 4). Random coils refer to the disordered and rapidly fluctuating set of conformation assumed by denatured protein and other proteins in solution (Rungwala et al., 2011).

Table.1 Tyrosinase gene family retrieved from UNIPROTKB

\begin{tabular}{|l|l|l|l|}
\hline S.NO & $\begin{array}{l}\text { ACCESSION } \\
\text { NUMBER }\end{array}$ & SEQUENCE DESCRIPTION & \multirow{2}{*}{ ORGANISM } \\
\cline { 1 - 2 } 01 & Q19VI0 & Tyrosinase & \multirow{2}{*}{ Salmo salar } \\
\cline { 1 - 2 } & Q19VI1 & Dopachrome tautomerase & \\
\hline 03 & Q19VH9 & Tyrosinase-related protein 1 & \multirow{2}{*}{ Teratodon nigrovirdis } \\
\hline 04 & H3CX59 & Tyrosinase & \\
\hline 05 & H3D173 & Tyrosinase-related protein 1 & \\
\hline 06 & H3BZP5 & Dopachrome tautomerase & \\
\hline
\end{tabular}


Table.2 Amino acid composition of considered Tyrosinase (in percentage) computed using the ExPasy tool

\begin{tabular}{|c|c|c|c|c|c|c|c|c|c|c|c|c|c|c|c|c|c|c|c|c|c|}
\hline S.NO & $\begin{array}{l}\text { Accession } \\
\text { Number }\end{array}$ & Ala & Arg & Asn & Asp & Cys & Gln & Glu & Gly & His & Ile & Leu & $\begin{array}{c}\mathbf{L y} \\
\mathbf{s}\end{array}$ & Met & Phe & Pro & Ser & Thr & Trp & Tyr & Val \\
\hline 01 & Q19VI0 & 5.9 & 6.6 & 4.6 & 4.6 & 2.8 & 4.1 & 5.3 & 9.4 & 2.8 & 3.3 & 8.7 & 1.3 & 3.5 & 5.2 & 5.7 & 6.8 & 7.0 & 2.2 & 4.4 & 5.9 \\
\hline 02 & Q19VI1 & 5.4 & 5.6 & 6.4 & 6.8 & 3.1 & 3.1 & 3.9 & 7.7 & 3.1 & 3.1 & 9.8 & 2.9 & 1.4 & 6.0 & 5.6 & 7.7 & 6.4 & 1.9 & 3.5 & 6.8 \\
\hline 04 & H3CX59 & 6.9 & 7.4 & 5.0 & 6.7 & 2.8 & 3.3 & 4.6 & 7.2 & 3.1 & 1.7 & 10.4 & 2.0 & 2.6 & 4.4 & 6.7 & 8.3 & 4.3 & 3.0 & 3.5 & 6.1 \\
\hline 05 & H3D173 & 7.9 & 7.4 & 5.3 & 5.9 & 3.2 & 4.7 & 4.0 & 7.8 & 3.0 & 3.8 & 6.0 & 1.1 & 1.7 & 5.7 & 7.2 & 6.8 & 5.5 & 1.9 & 3.4 & 7.8 \\
\hline 06 & H3BZP5 & 5.4 & 6.4 & 6.7 & 5.6 & 3.1 & 3.1 & 5.0 & 7.5 & 2.5 & 4.2 & 10.0 & 2.1 & 1.3 & 6.7 & 6.4 & 6.9 & 5.8 & 1.9 & 3.1 & 6.2 \\
\hline
\end{tabular}

Table.3 The physicochemical parameter of considered Tyrosinase is computed using the ExPasy ProtParam tool

\begin{tabular}{|c|c|c|c|c|c|c|c|c|c|c|}
\hline S. NO. & $\begin{array}{l}\text { Accession } \\
\text { Number }\end{array}$ & $\begin{array}{c}\text { No of amino } \\
\text { acid }\end{array}$ & M. wt. & PI & (-) $R$ & (+) $R$ & EC & II & AI & GRAVY \\
\hline 01 & Q19VI0 & 543 & 60985.88 & 5.77 & 54 & 43 & 102635 & 47.60 & 69.67 & -0.286 \\
\hline 02 & Q19VI1 & 518 & 57980.18 & 5.80 & 55 & 44 & 82820 & 38.81 & 75.44 & -0.291 \\
\hline 03 & Q19VH9 & 422 & 47576.38 & 5.44 & 43 & 31 & 75205 & 47.04 & 75.09 & -0.307 \\
\hline 04 & H3CX59 & 540 & 60982.65 & 5.95 & 61 & 51 & 117185 & 54.98 & 71.52 & -0.413 \\
\hline 05 & H3D173 & 529 & 58929.13 & 6.15 & 52 & 45 & 82820 & 43.07 & 68.75 & -0.328 \\
\hline 06 & H3BZP5 & 519 & 58430.01 & 5.66 & 55 & 44 & 79840 & 41.25 & 78.88 & -0.230 \\
\hline
\end{tabular}

Table.4 Transmembrane region identified by SOSUI Server

\begin{tabular}{|c|c|c|c|c|c|c|}
\hline S.No & Accession number & $\mathbf{N}$ terminal & Transmembrane region & C terminal & Type & Length \\
\hline 01 & Q19VI0 & 1 & MVLLVVLGSLLQMLFLRSCVGQF & 23 & PRIMARY & 23 \\
\hline & & 481 & QWLLGAGLIGAILAGIVMTTGAL & 503 & PRIMARY & 23 \\
\hline $\mathbf{0 2}$ & Q19VI1 & 468 & VFVLGSTLGGVFLGLLVLLLVLV & 490 & PRIMARY & 23 \\
\hline $\mathbf{0 3}$ & Q19VH9 & 366 & TEIITIAMVAALVIVAVIFAATT & 388 & PRIMARY & 23 \\
\hline 04 & H3CX59 & 1 & QPALMWLVIFTGILLNVTPSHQQ & 23 & PRIMARY & 23 \\
\hline 05 & H3D173 & 4 & RVWIMLARCVFLLLSAAVVRAQF & 26 & PRIMARY & 23 \\
\hline 06 & H3BZP5 & 474 & TEIITMGVVIALVVVAVIFAATT & 496 & PRIMARY & 23 \\
\hline
\end{tabular}


Table.5 Calculated secondary structure elements by SOPMA Server

\begin{tabular}{|c|c|c|c|c|c|}
\hline S.NO & $\begin{array}{c}\text { Accession } \\
\text { Number }\end{array}$ & $\begin{array}{c}\text { Alpha } \\
\text { helix }\end{array}$ & Extended & Beta turn & Random coil \\
\hline 01 & Q19VI0 & 30.94 & 11.23 & 1.47 & 56.35 \\
\hline 02 & Q19VI1 & 27.99 & 13.51 & 2.90 & 55.60 \\
\hline 03 & Q19VH9 & 32.94 & 10.90 & 0.71 & 55.45 \\
\hline 04 & H3CX59 & 30.74 & 11.85 & 2.04 & 55.37 \\
\hline 05 & H3D173 & 29.11 & 10.78 & 2.27 & 57.84 \\
\hline 06 & H3BZP5 & 25.63 & 13.49 & 2.41 & 58.57 \\
\hline
\end{tabular}

Table.6 Validation of modeled protein structure using different tools

\begin{tabular}{|l|l|l|l|}
\hline Servers & Property & Q19VIO & H3CX59 \\
\hline SWISS MODEL & & \multicolumn{2}{l|}{} \\
\hline ERRAT & Overall Quality factor & $\mathbf{9 1 . 4 4 2 5}$ & $\mathbf{8 9 . 3 3 6 5}$ \\
\hline Verify3D & (3D-1D score $>$ 0.2) & $\mathbf{9 2 . 2 4}$ & $\mathbf{9 2 . 9 1}$ \\
\hline PROCHECK & Residues in most favored regions & $\mathbf{8 6 . 1 \%}$ & $\mathbf{8 4 . 7 \%}$ \\
& Residues in additional allowed regions & $\mathbf{1 2 . 5 \%}$ & $\mathbf{1 4 . 2 \%}$ \\
& Residues in generously allowed regions & $\mathbf{1 . 4 \%}$ & $\mathbf{1 . 1 \%}$ \\
\hline CHIMERA 1.1.2 & Residues in disallowed regions & $\mathbf{0 . 0 \%}$ & $\mathbf{0 . 0 \%}$ \\
\hline ERRAT & Overall Quality factor & $\mathbf{5 8 . 8 6 2 1}$ & $\mathbf{5 4 . 9 7 8 4}$ \\
\hline Verify3D & (3D-1D score $>$ 0.2) & $\mathbf{7 7 . 5 3 \%}$ & $\mathbf{7 7 . 9 6 \%}$ \\
\hline PROCHECK & Residues in most favored regions & $\mathbf{8 9 . 5 \%}$ & $\mathbf{8 7 . 3 \%}$ \\
& Residues in additional allowed regions & $\mathbf{8 . 9 \%}$ & $\mathbf{1 1 . 0 \%}$ \\
& Residues in generously allowed regions & $\mathbf{1 . 1 \%}$ & $\mathbf{1 . 5 \%}$ \\
& Residues in disallowed regions & $\mathbf{0 . 4 \%}$ & $\mathbf{0 . 2 \%}$ \\
\hline
\end{tabular}

Figure.1 Kyte and Doolittle hydropathy plot for Tyrosinase of Salmo salar

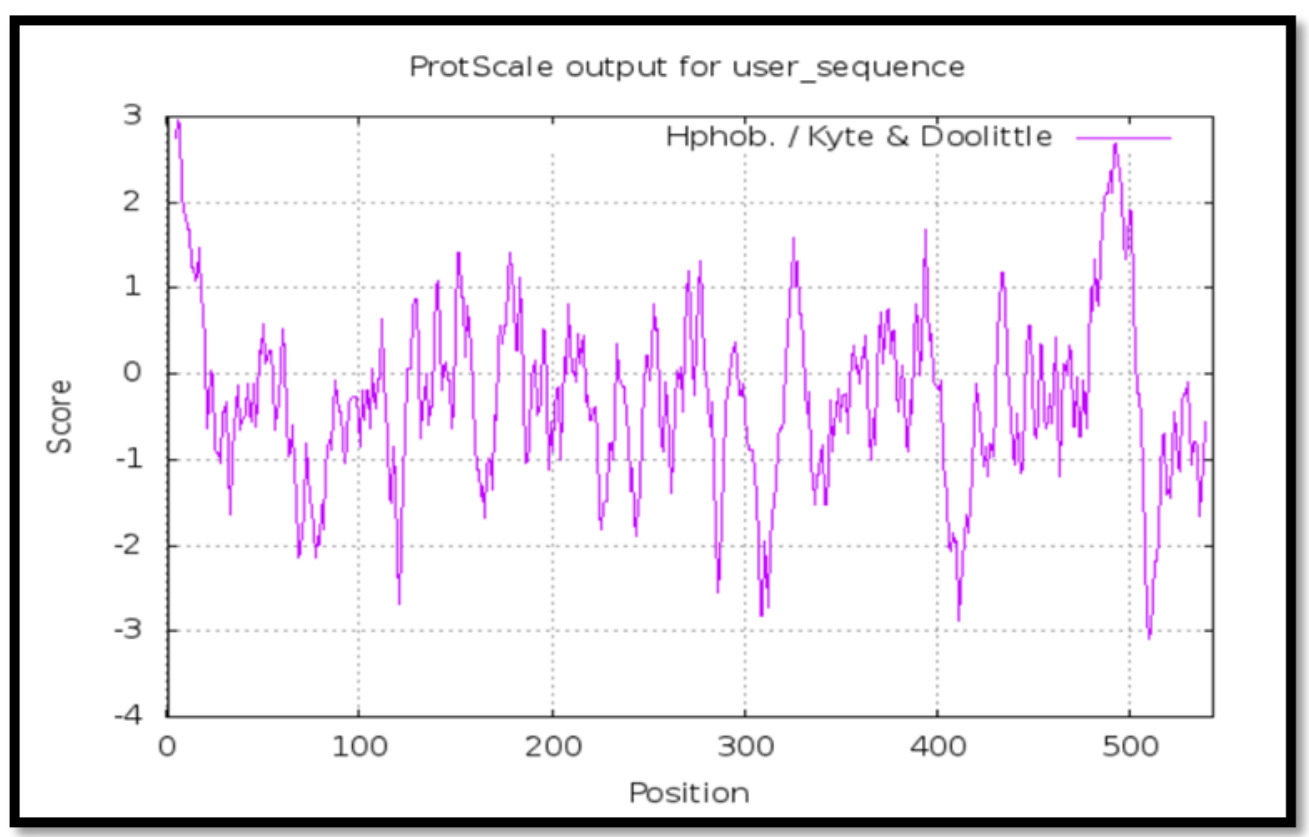


Fig.2 Ramachandran plot of the predicted Tertiary structure of Tyrosinase protein of Salmo salar (Q19VI0) by Procheck (Saves Server)

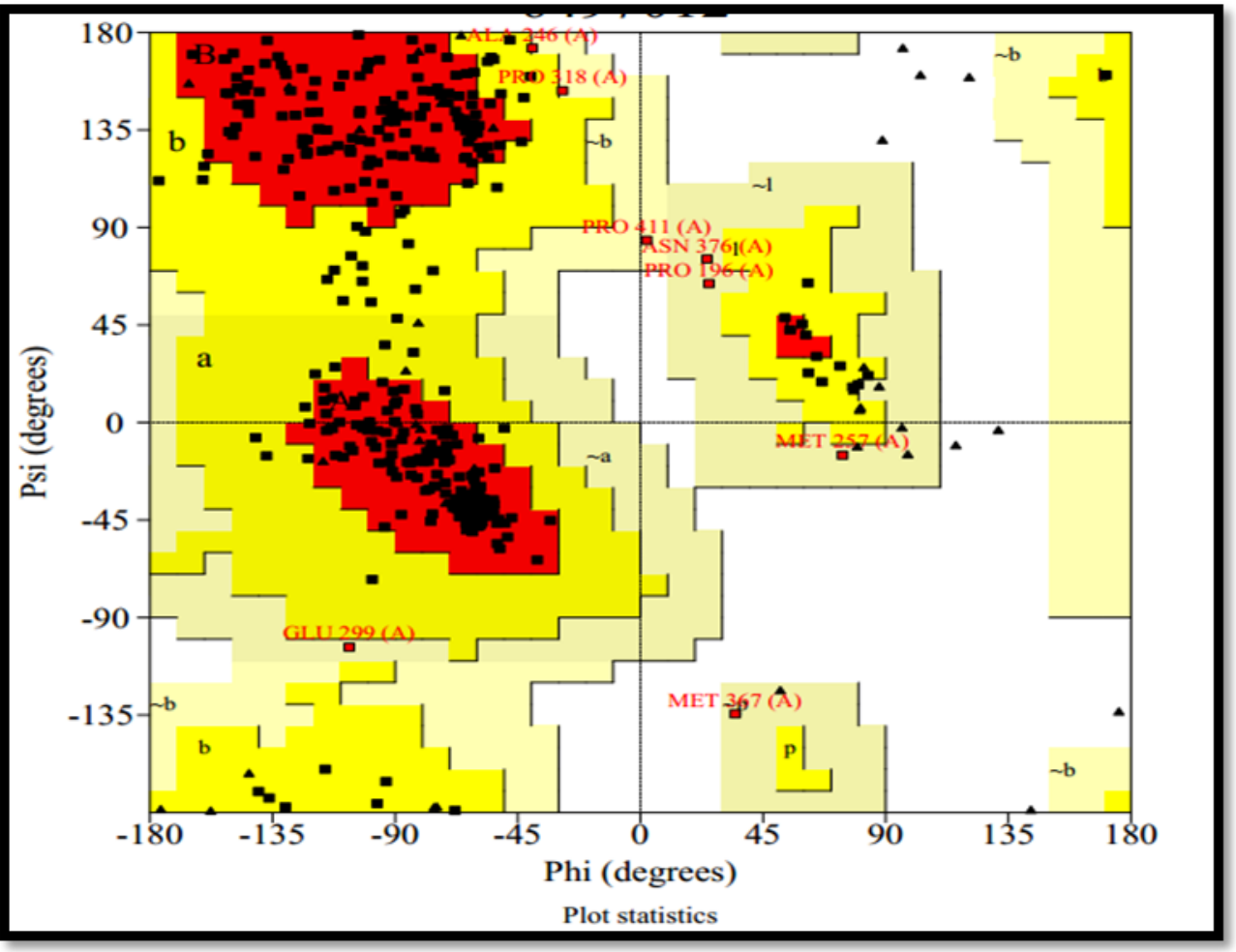

Fig.3 Ribbon representation of predicted tertiary structure of tyrosinase protein of Salmo salar using Swiss- model (Helix - cyan, Sheet- orange red, Loop - Magenta)

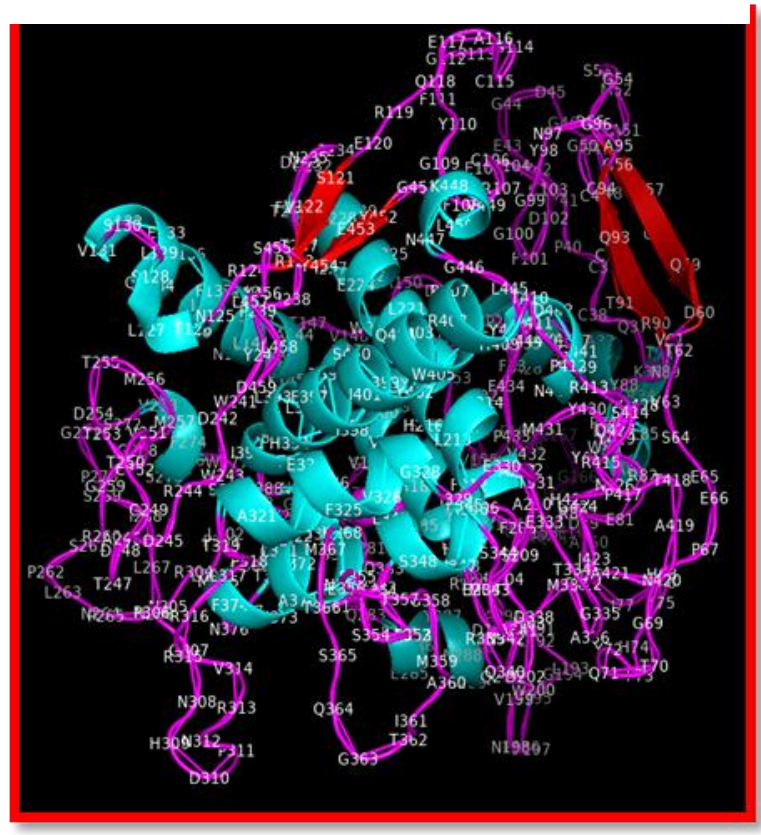

Fig.4 Surface representation of predicted tertiary structure of tyrosinase protein of Teratodon nigrovirdis using Swiss- model (Helix - cyan, Sheet- orange red, Loop - Magenta)

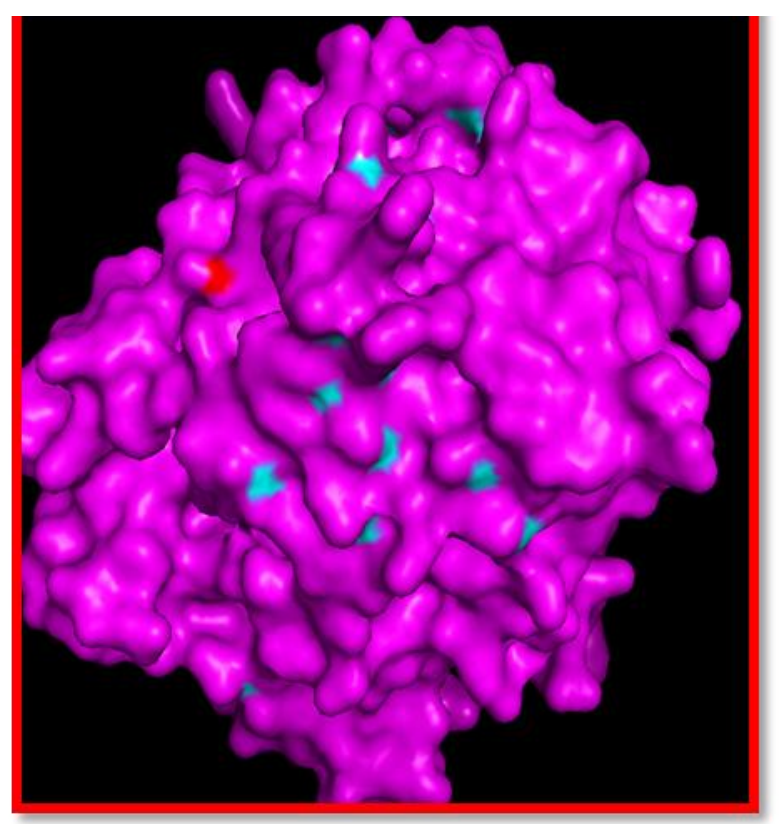


Table.7 Top 3 compound after virtual screening and toxic properties analysis

\begin{tabular}{|l|l|l|}
\hline S.NO & ZINC ID & BINDING EFFICIENCY $(\mathrm{kcal} / \mathrm{mol})$ \\
\hline 01 & ZINC35860 & $\mathbf{- 8 . 7 ~} \mathrm{kcal} / \mathrm{mol}$ \\
\hline 02 & ZINC00090084 & $\mathbf{- 8 . 5} \mathrm{kcal} / \mathbf{m o l}$ \\
\hline 03 & ZINC00119983 & $\mathbf{8 . 2} \mathrm{kcal} / \mathrm{mol}$ \\
\hline
\end{tabular}

Fig.5 Predicted Docked structure of Tyrosinase protein of Salmo salar using Autodock vina, Viewed in PyMol

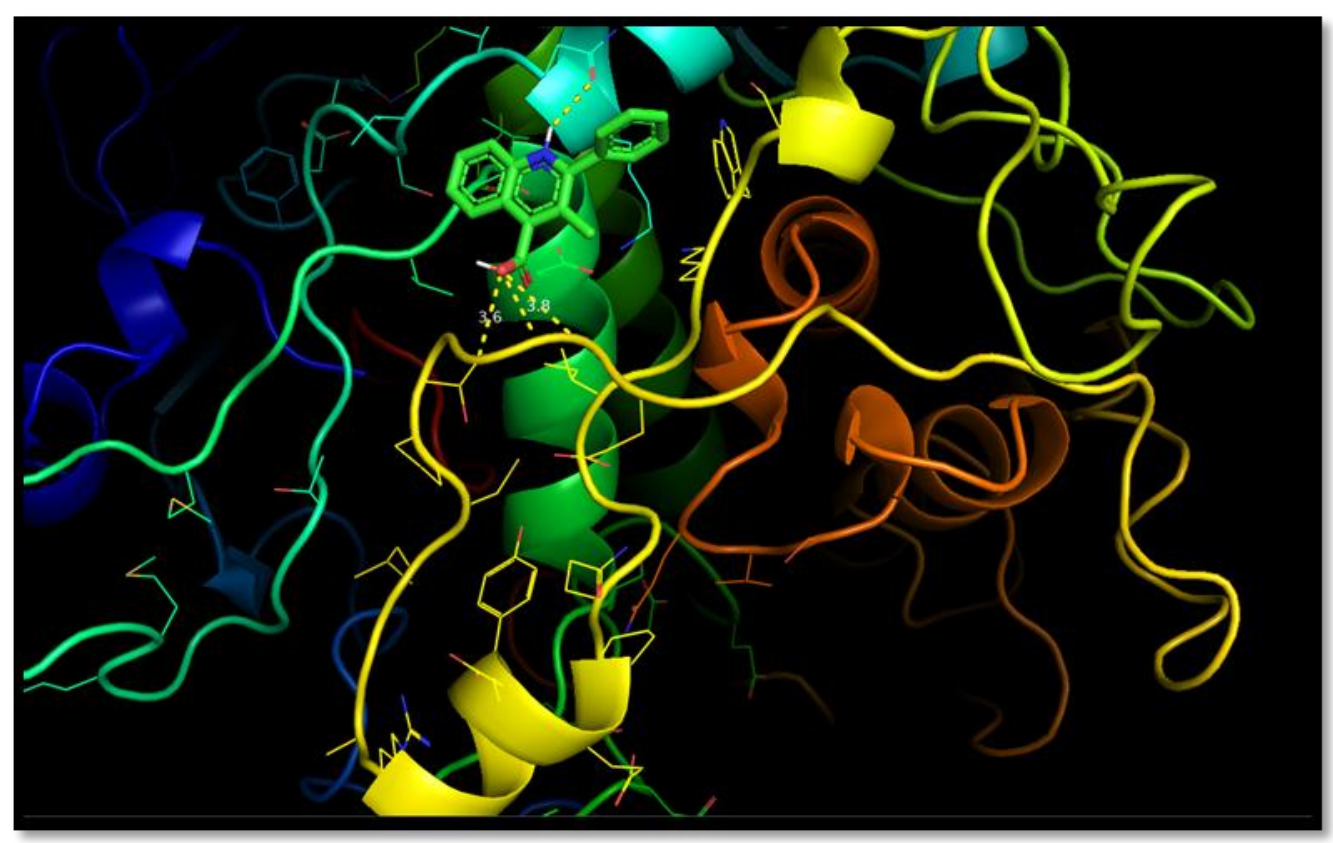

\section{Tertiary structure prediction}

SWISSMODEL was used to predict the 3D structures of proteins. $5 \mathrm{~m} 81.1 \quad(5,6-$ dihydroxyindole-2-carboxylic acid oxidase) were selected as templates from the PDB database for Q19VI0 and H3CX59 respectively based on sequence identity $(45.14 \%$ and $45.71 \%)$. The final modeled structures are shown in Figure 2. The amino acid residues $86.1 \%$ and $84.7 \%$ lie in the most favored regions of Ramachandran Plot as revealed by PROCHECK analysis for the structure modeled for Q19VI0 and H3CX59 respectively. The predicted structures conformed well to the stereochemistry indicating reasonably good quality and were used for further analysis.

\section{Grid box dimension}

Tyrosinase protein sequence of Salmo salar and Teratodon nigrovirdis was selected for virtual screening against 13000 compounds downloaded from the Zinc database. The grid box parameter values were adjusted to confirm the maximum binding affinity and best conformational pose of ligand - protein complexes. The grid parameter values for Salmo salar and Teratodon nigrovirdis tyrosinase were adjusted into specific coordinates having center_x (37.2354832692), center_y (29.5828041517), center_z (-17.6576), size_x (62.0255238487), size_y $=(63.5933591266)$, size $\_z=(25.0000)$ in angstrom. 


\section{Virtual screening}

A virtual screening experiment was employed on all ligands against the predicted structure of Salmo salar and Teratodon nigrovirdis tyrosinase by Autodock vina. The protein ligand docked complexes were further evaluated on the lowest binding energy (kcal/mol) values. The best docked energy complexes with the lowest binding values were visualized in PyMol. The estimated ADME properties proved that selected compounds were suitable for usage in fishes. Three compounds out of 13000 from the ZINC database were identified as putative modulators of fish tyrosinase having binding energy $-8.7 \mathrm{Kcal} / \mathrm{mol}$ to $-8.2 \mathrm{Kcal} / \mathrm{mol}$ and rmsd 0.000 from lower bound as well as upper bound. Among which, 3-Methyl-2phenylquinoline-4-carboxylic acid, 2-(4chlorobenzyl)-5-(3-nitrophenyl)-2H-1,2,3,4tetraazole and Kaempferol were considered as potential putative modulators as they had low binding energy and had acceptable properties for standardized drugs.

In conclusion, the knowledge acquired by the results of the predicted tertiary structure of Salmo salar and Teratodon nigrovirdis Tyrosinase protein provides an insight into tyrosinase protein structure and function. The Salmo salar and Teratodon nigrovirdis tyrosinase protein is hydrophobic in nature due to the presence of non-polar residue.

The identified modulators may be significance to determine its modulating activity in the treatment of some dermatological diseases associated with melanin hyper pigmentation in human as well as food fishes, preventing undesirable browning of fruits and vegetables that change their color, taste, and nutritive values occur as a result of over activity of the enzyme.

\section{Acknowledgements}

The authors would like to thank the Director,
ICAR- Central Institute of Fisheries Education, Mumbai, India for providing the facility to carry this work. The first author also acknowledges the financial support provided by the ICAR, New Delhi in the form of Junior Research Fellowship (JRF).

\section{References}

Artés, F., Castañer, M. and Gil, M.I., 1998. Revisión: El pardeamiento enzimático en frutas $\mathrm{y}$ hortalizas mínimamente procesadas Review: Enzymatic browning in minimally processed fruit and vegetables. Food science and technology international, 4(6), pp.377389.

Ashraf, Z., Rafiq, M., Seo, S.Y. and Babar, M.M., 2015. Synthesis, kinetic mechanism and docking studies of vanillin derivatives as inhibitors of mushroom tyrosinase. Bioorganic \& medicinal chemistry, 23(17), pp.58705880.

Bagherzadeh, K., Shirgahi Talari, F., Sharifi, A., Ganjali, M.R., Saboury, A.A. and Amanlou, M., 2015. A new insight into mushroom tyrosinase inhibitors: docking, pharmacophore-based virtual screening, and molecular modeling studies. Journal of Biomolecular Structure and Dynamics, 33(3), pp.487501.

Garcia de Leaniz, C., Fleming, I.A., Einum, S., Verspoor, E., Jordan, W.C., Consuegra, S., Aubin- Horth, N., Lajus, D., Letcher, B.H., Youngson, A.F. and Webb, J.H., 2007. A critical review of adaptive genetic variation in Atlantic salmon: implications for conservation. Biological reviews, 82(2), pp.173-211.

Hasegawa, T., 2010. Tyrosinase-expressing neuronal cell line as in vitro model of Parkinson's disease. International journal of molecular sciences, 11(3), pp.1082-1089.

Halaban, R., Patton, R.S., Cheng, E., Svedine, 
S., Trombetta, E.S., Wahl, M.L., Ariyan, S. and Hebert, D.N., 2002. Abnormal acidification of melanoma cells induces tyrosinase retention in the early secretory pathway. Journal of Biological Chemistry, 277(17), pp.14821-14828.

Hirokawa, T., Boon-Chieng, S. and Mitaku, S., 1998. SOSUI: classification and secondary structure prediction system for membrane proteins. Bioinformatics (Oxford, England), 14(4): 378-379.

Rao, A.R., Sindhuja, H.N., Dharmesh, S.M., Sankar, K.U., Sarada, R. and Ravishankar, G.A., 2013. Effective inhibition of skin cancer, tyrosinase, and antioxidative properties by astaxanthin and astaxanthin esters from the green alga Haematococcus pluvialis. Journal of agricultural and food chemistry, 61(16), pp.3842-3851.
Wang, J., Hou, L., Zhang, R., Zhao, X., Jiang, L., Sun, W., An, J. and Li, X., 2007. The tyrosinase gene family and albinism in fish. Chinese Journal of Oceanology and Limnology, 25: 191198.

http://autodock.scripps.edu/downloads/ autodock-registeration/autodock-4.2download-page/ http://us.expasy.org/tools/protparam. html https://npsa-prabi.ibcp.fr/NPSA/npsa _sopma.htmlhttps://salilab.org/modeller / https://services.mbi.ucla.edu/SAVES/ https://swissmodel.expasy.org/ www.scfbioiitd.res.in/softwarel drugdesign/lipinski.jsp

www.uniprot.org/ zinc.docking.org

\section{How to cite this article:}

Riya Kumari and Sujit Kumar. 2020. In silico Characterization, Homology Modeling and Virtual Screening of Selected Natural Compounds as Modulators of Salmo salar and Teratodon nigrovirdis Tyrosinase Protein. Int.J.Curr.Microbiol.App.Sci. 9(03): 1172-1181. doi: https://doi.org/10.20546/ijcmas.2020.903.137 